\title{
Palabras de Presentación
}

EI Programa de Formación de capacidades en Ciencia, Tecnología e Innovación en el Departamento de Sucre, Caribe, surge como una estrategia para apoyar la Formación de Alto Nivel (FAN) del capital humano del Departamento de Sucre, en el marco de la Política Nacional de Fomento a la Investigación y la Innovación "Colombia Construye y Siembra Futuro" que estableció la generación, difusión y uso del conocimiento como una condición fundamental para la modernización del sistema productivo y el incremento de los niveles de innovación y competitividad del país. Y como parte de esta política, se implementó la estrategia de apoyar la formación de 3.600 profesionales en el nivel de doctorado, de manera que Colombia pueda contar con un recurso humano con fortalezas para la investigación y la innovación (Colciencias, 2008, CONPES 3527 de 2008 y 3582 de 2009).

Dentro de este contexto, el Programa de Formación de Alto Nivel del departamento de Sucre, tiene como propósito incrementar la disponibilidad de capital humano con capacidades para la ciencia, la tecnología y la innovación para contribuir al mejoramiento de la productividad y competitividad del Departamento y la Región. Este Programa se desarrolló mediante de la alianza Colciencias / Departamento de Sucre, con recursos del Fondo de Ciencia, Tecnología e Innovación (FCTeI) del Sistema General de Regalías (SGR) y la aprobación del Órgano Colegiado de Administración y Decisión (OCAD) del FCTeI el 19 de julio de 2013.

Esencialmente, el Programa busca incentivar a profesionales sucreños con interés en su formación investigativa y crear condiciones favorables de un nicho científico que les permitiera articularse para generar propuestas que representen un aporte a la región en las áreas estratégicas previamente identificadas, para lo cual se seleccionaron 20 núcleos problema en los sectores económicos priorizados para Sucre; se formaron 12 doctores en Brasil y 200 magister en tres universidades de la Región Caribe, a saber: 
La universidad de Córdoba, la Universidad del Norte, y la Universidad Tecnológica de Bolivar. De esta manera, el Programa pretende contribuir a la superación de las falencias que, en materia de ciencia, tecnología e innovación, padece el Departamento, tales como:

- La escasez en el número de doctores y magísteres formados en áreas afines a los sectores económicos priorizados por la agenda regional de competitividad;

- La desarticulación en la relación Universidad - Empresa- Estado para el desarrollo de programas conducentes a la solución de problemáticas sectoriales del departamento; y

- La baja cobertura y articulación entre los programas de investigación formativa como la de jóvenes investigadores, semilleros de investigación y Ondas (Proyecto de Formación de Alto Nivel Departamento de Sucre, 2017),

La estrategia del Programa consistió en la vinculación de los directores de cada núcleo, los estudiantes de las diferentes maestrías y los jóvenes investigadores, como ejecutores de los productos asociados a las actividades de cada núcleo, articulando las características y los objetivos de cada núcleo, con los intereses de los maestrantes, las líneas de investigación de las maestrías, y la experticia de los directores de núcleo y docentes de las universidades participantes en el proceso formativo, tal como se observa en la Figura 1.

Figura 1. Esquema de la estrategia operativa del Programa

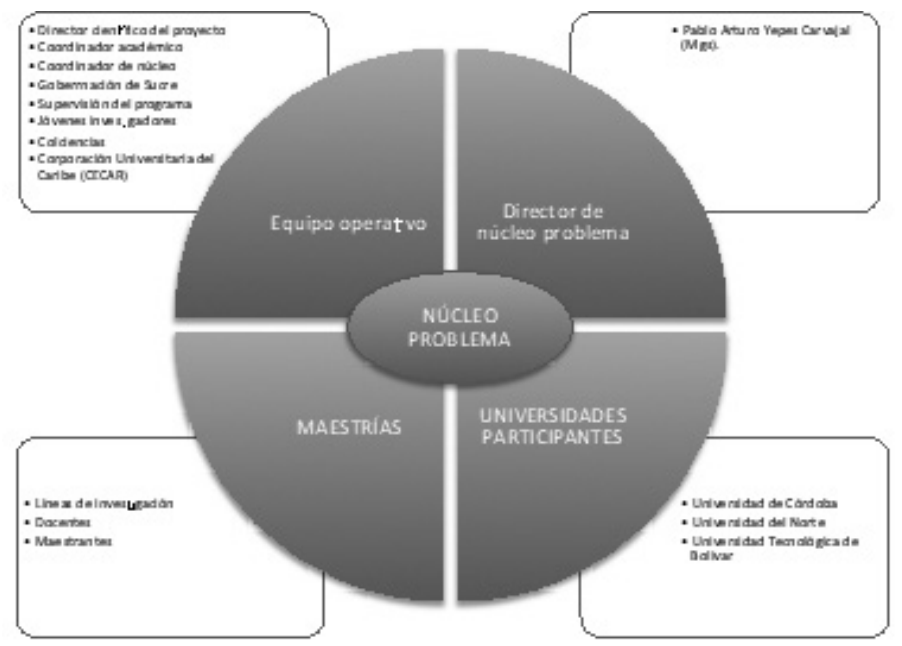


Con la puesta en marcha de la estrategia anteriormente descrita, se inició el desarrollo del Programa, en el cual se pudieron llevar a cabo varios proyectos, de los cuales se presentan en este libro los hallazgos generados desde el núcleo problema No. 16, denominado "Desarrollo Urbano y Económico de Sincelejo", orientado a presentar soluciones alternativas para la toma de decisiones por parte de los responsables de la gestión del espacio público en el municipio de Sincelejo. Pues, antes de que el Concejo Municipal de Sincelejo, por unanimidad, en diciembre de 2015, avalara el Plan de Ordenamiento Territorial de Segunda Generación, en el marco del Proyecto de Formación de Alto Nivel (FAN) del Departamento de Sucre, iniciado en el año 2013, y desde este núcleo problema, se comenzó a trabajar desde la perspectiva urbana y económica del municipio. Sin embargo, por tratarse de una temática amplia se llevó a cabo una pre-investigación con el propósito de determinar la problemática más crítica y a la que, por medio de conclusiones, se le pudiesen proponer soluciones alternativas a las entidades gubernamentales encargadas de la toma de decisiones en el ente territorial.

De esta manera, se determinó que el espacio público del municipio era eje el apropiado para direccionar la pesquisa, y por lo tanto, se debían establecer lineamientos o estrategias propositivas que sirviesen como herramientas para que los administradores municipales, pudiesen darle solución a la problemática general del espacio público en el municipio de Sincelejo.

En el imaginario colectivo, cuando se habla o menciona el espacio público solo se percibe la idea de los senderos peatonales, sin alcanzar la magnitud total que abarca este término. Se obvia, por demás, lo intrínseco que este término tiene respecto a los ríos, montañas, valles, quebradas, etc.; como elementos naturales. Así mismo, no se entiende que las calles, andenes, ciclo rutas, parques, plazas, y plazoletas, entre otros, hacen parte de los elementos constitutivos artificiales y que, además, existen elementos complementarios a todos los mencionados. Es decir, que, a grandes rasgos, Espacio Público, va más allá de lo que el ciudadano común entiende.

La falta de la calidad adecuada del espacio público, entendido en sus elementos: natural, artificial y complementario, genera como 
consecuencia una falta de conciencia ciudadana hacia su cuidado, y por ende, el usufructo desesperado y desaforado de éste.

"La complejidad de la ciudad, de la vida social y de la configuración urbana" Lefebvre.

Consecuente con lo anterior, el proyecto se enfoca, en general, desde una perspectiva social y económica, mucho más allá de lo que comúnmente se espera, que sería no más que planos propositivos, con dimensiones, especificaciones técnicas, y detalles constructivos, entre otros.

La perspectiva económica parte del hecho de que la invasión del espacio público, está expresada en términos de la informalidad laboral y la generación de ingresos. Mientras que la visión social se da por la contextualización de la sociedad que lo invade, que lo usufructúa, que lo vive $y$, finalmente, la comunidad que carece de estos espacios de recreación, ocio, paisaje, y recorrido, entre otros.

Además de lo urbano arquitectónico, dentro de la complejidad del espacio público, convergen la realidad social y económica que contextualiza a las comunidades que usan estos espacios; entendiendo entonces que todos estos aspectos tienen una conectividad directamente proporcional.

En este proyecto, se da paso al análisis del espacio público desde la perspectiva social y económica, con gran énfasis en la invasión de este y se hace un recorrido teórico - legal que enmarca la temática en Colombia y el mundo, para una mayor comprensión de la relación del espacio público con calidad de vida, el mercado laboral, la eficiencia económica y el espacio público como tal.

Seguidamente se da paso a un análisis urbano de las cuatro principales ciudades de Colombia: Bogotá, Cali, Medellín y Barranquilla, y las dos ciudades consideradas por entes internacionales como ejemplos de desarrollo sostenible: Bucaramanga y Medellín, a modo de entender las buenas prácticas en el mejoramiento del espacio público y todos sus elementos.

Luego, se realiza un análisis del espacio público del Municipio de Sincelejo desde la lupa del Plan de Ordenamiento Territorial y 
desde una evaluación etológica y descriptiva, en dos zonas específicas con grandes crisis de invasión del espacio público: Centro Histórico - CHS y Avenida Ocala, para finalmente presentar las conclusiones y recomendaciones que cierran con una propuesta de estrategias que puedan ser usadas como herramientas para la solución al problema de espacio público en el Municipio de Sincelejo. 